\title{
The Tree of life: Banned or Not Banned? A Rational
}

\section{Choice Interpretation}

Dr. Sigmund Wagner-Tsukamoto

School of Management

University of Leicester

University Road

Leicester LE1 7RH, UK

Email: sawt444@aol.com 


\title{
The Tree of life: Banned or Not Banned? A Rational Choice Interpretation
}

\begin{abstract}
Literal biblical interpretation advocates the view that at the outset of the paradise story Adam and Eve were only banned to eat of the tree of knowledge. The present paper challenges this view through an economic, rational choice interpretation and the application of a self-interested decision calculus (model of economic man). I mount the thesis that, on grounds of a rational choice reconstruction, Adam and Eve must have been implicitly banned from the outset not to eat of the tree of life, despite no explicit ban being stated in Genesis. The paper argues for the validity and insightfulness of such a rational choice analysis of the paradise story, which considerably clarifies the conceptual logic and structure of the Eden story.
\end{abstract}

\section{KEYWORDS}

Tree of life; ban regarding the tree of life; Genesis 2-3; rational choice theory; model of self interest (homo economicus) 


\section{The Tree of life: Banned or Not Banned? A Rational}

\section{Choice Interpretation}

The old question whether the enjoyment of the tree of life was open to man - should we wish to ask it all - will have to be answered affirmatively, primarily on the basis of the related ancient Oriental ideas. ${ }^{1}$

The issue ... is what is heuristically fruitful in guiding the mind to a better understanding of the biblical text. ... What matters is a constant dialectical sifting of preunderstanding and proposed interpretation alike, in the attempt to articulate an understanding of the text that may rightly be found persuasive. ${ }^{2}$

\section{Introduction}

In biblical interpretation, both mainstream theological exegesis and modern or postmodern, critical approaches, it is generally accepted that Adam and Eve were only banned to eat of the tree of knowledge when the story of the theft unfolds. ${ }^{3}$ Biblical interpretation here

\footnotetext{
${ }^{1}$ See Gerhard von Rad, Genesis. A Commentary (London, 1963), pp. 79-80.

${ }^{2}$ See R. W. L. Moberley, "Did the Interpreters Get It Right? Genesis 2-3 Reconsidered", JTS 59 (2008)L: 39-40.

${ }^{3}$ See Rad, Genesis, 79-80; R. Davidson, Genesis 1-11 (Cambridge, 1973), pp. 33-35; David Jobling, "The Myth Semantics of Genesis 2:4b-3:24", Semeia 18 (1980): 47; David Jobling, "Myth and its Limits in Genesis 2.4b-3.24", in The Sense of Biblical Narrative. II. Structural Analyses of the Hebrew
} 
takes up the literal treatment of the subject in Gen. 2:17 when God explicitly put forward only a ban regarding the tree of knowledge, telling Adam and Eve that they will die should they break the ban. Whether this meant the taking away of a previously held privilege of Adam and Eve to immortality in paradise ${ }^{5}$, or an immediate death sentence ${ }^{6}$, a threat or warning of some kind of sanctions in the case of a transgression", or even an "empty, misleading" threat ${ }^{8}$ is a critical question. In this respect, the tree of life and the issue of "life and death" may or may not connect to the ban of Gen. 2:17 regarding the tree of knowledge.

Some literature hints, although without any explicit treatment of this issue, that a ban not to eat of the tree of life also existed from the outset, specifically when the proposal of immortality is put forward as a divine prerogative in the paradise story. ${ }^{9}$ God's status of

Bible (ed. David Jobling, Sheffield: JSOTSS 39, 1986), p. 31; James K. West, Introduction to the Old Testament (New York: Macmillan, 1981), 87; Claus Westermann, Genesis 1-11. A Commentary (London: SPCK, 1984), p. 272; R. W. L. Moberley, “Did the Serpent Get It Right?”, JTS 39 (1988), 4; Sam Dragga, "Genesis 2-3: A Story of Liberation", JSOT 55 (1992), 4; Beverly J. Stratton, Out of Eden. Reading, Rhetoric, and Ideology in Genesis 2-3 (JSOTSS 208; Sheffield: Academic Press, 1995), 64, 218-19; James L. Kugel, The Bible as It Was (Cambridge: Belknap/Harvard University Press, 1997), 69.

${ }^{4}$ All Bible quotations refer to the Holy Bible. New International Version ${ }^{\circledR}$. NIV ${ }^{\circledR}$. Copyright $\left({ }^{\circ} 1973\right.$, 1978,1984 by International Bible Society $\mathbb{C}$. All rights reserved worldwide. Used by permission of Hodder \& Stoughton Publishers, A member of the Hachette Livre UK Group. All rights reserved. 'NIV' is a registered trademark of International Bible Society. UK trademark number 1448790.

${ }^{5}$ See Rad, Genesis; Jobling, "Myth Semantics”; Kugel, Bible.

${ }^{6}$ See Moberley, "Serpent"; Jutta Krispenz, "Wie viele Bäume braucht das Paradies? Erwägungen zu Gen II 4B-III 24", VT 54 (2004): 301-318.

${ }^{7}$ See Sigmund A. Wagner-Tsukamoto, Is God an Economist? An Institutional Economic Reconstruction of the Old Testament (Basingstoke, UK, New York et al.: Palgrave Macmillan, 2009).

${ }^{8}$ See Moberley, “Interpreters"; Moberley, "Serpent", 10.

${ }^{9}$ See Benedikt Otzen, Hans Gottlieb and Knud Jeppsen, Myths in the Old Testament (London: SCM, 1980), 47. 
"being divine" is set out through the two prerogatives of ultimate knowledge and immortality, as reflected by the two paradisiacal trees in the middle of the Garden: "Man could become God if only he were to eat from the tree of knowledge and the tree of life."10 Hence, Adam and Eve could only turn into gods should they succeed to acquire both ultimate knowledge and eternal life. Two separate "requirements" and two essential motives can in this regard be identified in the paradise story. As much as Westermann attests that "wisdom" and "eternal life" set out divinity ${ }^{11}$, he, however, unconvincingly claims in this connection that the two trees were logically unconnected..$^{12}$ I agree with him that the two trees reflect two separate motives but I disagree that the trees were logically unconnected: The logical connection that exists between them was clearly realized, for instance, by Fromm, as quoted above - Adam and Eve turning into gods should they succeed to eat of both trees.

Theological interpretation also hinted at a ban for the tree of life, specifically so when characterizing the serpent as the guardian of the tree of life who "shielded the fruit of immortality with words" from Adam and Eve: in this connection, interpreters suggested that the tree of life was unattainable but not banned. ${ }^{13}$ However, there is nothing explicitly stated in Genesis regarding a guarding function of the serpent for the tree of life. Nevertheless, it is worthwhile noting that a "guardian" is not a physical impediment. Rather,

\footnotetext{
${ }^{10}$ Erich Fromm, You Shall Be as Gods. A Radical Interpretation of the Old Testament and Its Tradition (London: Jonathan Cape, 1967), 22, emphasis as in original; see also ibid., 64, 159; Davidson, Genesis 1-11, 46-8; Jobling, "Myth and its Limits", 47; Westermann, Genesis 1-11, 272; Stratton, Out of Eden, 45 who refers to further literature on this issue.

${ }^{11}$ Westermann, Genesis 1-11, 272.

12 Ibid., 271.

${ }^{13}$ See Dragga, "Genesis 2-3", 12; similarly ibid., 7; Westermann, Genesis 1-11, 272.
} 
one has to ask the question of authority: On whose authority did the serpent supposedly guard the tree of life? It is hardly conceivable that the snake acted on own authority in this matter. How could she? Why should she? The only credible authority seems to be God who had created Eden. So, if one wanted to argue that the snake protected the tree of life, this leads back to the question of whether this tree was actually banned (rather than being permitted but not attainable).

These insights provide the starting point for a critical rational choice interpretation of the question whether Adam and Eve were banned, from the outset of the paradise story, not to eat of the tree of life. I advance the thesis that an implicit ban regarding the tree of life must be assumed in order to preserve not only the conceptual logic of the paradise story itself but also the theory building strategy of the Old Testament as it subsequently drives social analysis after the paradise story, especially on moral autonomy of humans and the social contracts they negotiate with God (the covenants) and among themselves. The paper mounts this thesis and builds its arguments by drawing on economic, rational choice theory, and here in particular the calculus of self-interested choice as it heuristically sets outs the model of economic man ("homo economicus").

The methodological approach followed by the paper links to the textual, narrative approach and, like Brett, I endorse methodological pluralism for interpreting the Old Testament. ${ }^{14}$ In our case, rational choice theory provides the textual interpretation and reading schema through which I analyse the paradise story. Although, I would cast the interpretative community to which this paper belongs much wider than rational choice

\footnotetext{
${ }^{14}$ See Mark G. Brett, "Reading the Bible in the Context of Methodological Pluralism", JSOTSS 299 (2000): 48-78.
} 
economics, particularly extending to fields like theology and the scientific study of religion. ${ }^{15}$ How to apply the textual approach to Old Testament analysis has been set out in more detail elsewhere ${ }^{16}$ However, it is worthwhile to recapitulate one or two ideas of textual, narrative analysis which are especially important for the present paper. I connect to Brett who differentiated three types of authorial purposes or intentions of the biblical text ${ }^{17}$ : First, he distinguished direct, explicit communicative intentions and purposes which are what an author is saying through the contents of the text ("text itself"); second, there are implied or indirect communicative intentions and purposes which are implications of the text about its contents, assumptions, etc. and which need to be deduced from the text ("deductions", "hypotheses"); third, motives can be identified which reflect reasons why an author is saying something, why text was created ("reasons why"). As explained, the key thesis of the present paper is that the Eden story rests on the underlying, implicit assumption that Adam and Eve were banned to eat of the tree of life from the outset of the paradise story. I will argue that theology has here too strongly focused on the contents of the text itself and what Brett termed direct, explicit communication. Hence, in order to develop my economic, rational choice critique I focus on implied, indirect intentions and on motives of the biblical text. In this way, I clarify Genesis 2-3. This also underlines that textual, literary

\footnotetext{
${ }^{15}$ See my discussion below, when I compare the image of human nature of economics and theology.

${ }^{16}$ See Sigmund A. Wagner-Tsukamoto, "The Paradise Story: A Constitutional Economic Reconstruction", JSOT 34.2 (2009), 149-152; see also Wagner-Tsukamoto, God, and the literature quoted on this issue.

${ }^{17}$ See Brett, "Reading", 59-60; see also Andrew D. H. Mayes, "On Describing the Purpose of Deuteronomy", JSOT 58 (1993), 17.
} 
interpretation, contrary to expectations of some interpreters ${ }^{18}$, still can considerably contribute to improve our understanding of the paradise story.

In a first part of the paper, I briefly introduce rational choice theory and the way I apply it to the paradise story. Subsequently, I analyse through a rational choice reconstruction the question of whether Adam and Eve were banned or not banned to eat of the tree of life from the outset of the story, i.e. once Adam and Eve began to exist in the Garden Eden. Finally, I offer some conclusions.

\section{Rational Choice Theory: A Brief Introduction}

Rational choice theory, in one variant or another, lies at the heart of economic analysis. It suggests that an individual optimizes personal gain for self-interested purposes when making a choice between decision alternatives. What is understood by "optimizing" is not too great a concern for the present paper, implying either some strict maximization of utilities or expected utilities, as found in classical and neoclassical economics, or merely some kind of "satisficing" calculus, as postulated by behavioural economics. ${ }^{19}$ The more significant element of rational choice which the paper draws upon is a calculus of selfinterested choice, as it essentially sets out the model of economic man ("homo economicus").

\footnotetext{
${ }^{18}$ For example, Rad, Genesis, p. 72.

${ }^{19}$ See Herbert A. Simon, "A Behavioral Model of Rational Choice", Quarterly Journal of Economics 69 (1955): 99-118; Herbert A. Simon, "From Substantive to Procedural Rationality", in Method and Appraisal in Economics (ed. Spiro J. Latsis, Cambridge: Cambridge University Press, 1976), 129-48.
} 
I do not suggest that the model of economic man reflects a realistic and morally satisfactory image of human nature in any empirical, behavioural sense, in particular that humans always and consistently acted or even should act according to the model of economic man. Behavioural economists and many researchers from other social sciences and the arts and humanities have - in my view, wrongfully - accused in this respect the model of economic man as unrealistic, gloomy and immoral. ${ }^{20}$ As I have argued elsewhere ${ }^{21}$, such criticism misses its target since the model of economic man is, in the first instance, not meant to portray "human nature as we know it" - a maxim to which behavioural economists like Simon, North, Sen or Williamson claim to subscribe.

I draw on rational choice theory and the model of economic man in the way as it is set out methodologically but not empirically or behaviourally. ${ }^{22}$ From the outset, I want to stress that I understand the model of rational choice as a methodological tool or "fiction" or

\footnotetext{
${ }^{20}$ For instance, Simon, "Behavioral Model"; Simon, "Procedural Rationality"; Douglas C. North, Institutions, Institutional Change and Economic Performance (Cambridge: Cambridge University Press, 1990); Amartya K. Sen, "Rational Fools: A Critique of the Behavioral Foundations of Economic Theory", in Beyond Self-Interest (ed. Jane J. Mansbridge, Chicago: University of Chicago Press, 1990), 25-43; Oliver E. Williamson, The Economic Institutions of Capitalism (New York: Free Press, 1985).

${ }^{21}$ See Sigmund A. Wagner-Tsukamoto, Human Nature and Organization Theory: On the Economic Approach to Institutional Organization (Cheltenham, UK and New York: E. Elgar, 2003). See also Wagner-Tsukamoto, God; Sigmund A. Wagner-Tsukamoto, "Out of a Slave Contract. The Analysis of Pre-Hobbesian Anarchists in the Old Testament", Constitutional Political Economy 21 (2010): 288307.

${ }^{22}$ See Gary S. Becker, The Economic Approach to Human Behavior (Chicago: University of Chicaho Press, 1976); Gary S. Becker, "The Economic Way of Looking at Behavior", Journal of Political Economy 101 (1993): 385-409; Fritz Machlup, Methodology of Economics and Other Social Sciences (New York: Academic Press, 1978); James M. Buchanan, "The Constitution of Economic Policy", American Economic Review 77 (1987), 243-250; Karl Homann and Andreas Suchanek, "Methodologische Überlegungen zum ökonomischen Imperialismus", Analyse \& Kritik. Zeitschrift für Sozialwissenschaften 11 (1989): 70-93; Karl Homann, "Homo Oeconomicus und Dilemmastrukturen," in Wirtschaftspolitik in offenen Volkswirtschaften (ed. Hermann Sautter, Göttingen: Vandenhoeck \& Ruprecht, 1994), 387-411; Wagner-Tsukamoto, Human Nature.
} 
"research heuristic", to use a more technical term. This tool guides, instructs and underwires economic analysis; it is beyond empirical and moral criticism - but not so the theory developed and the practical interventions achieved through applying this tool. At the level of theory building and practical intervention, economics is open to empirical and moral scrutiny, focusing on economic concepts such as capital exchange and incentive structures. In these latter respects, economics achieves empirically valid and morally sound results. ${ }^{23}$

Methodologically, I mount the thesis that other social sciences do not proceed differently than economics when applying models of human nature. Dahrendorf openly attested to this when characterizing the homo sociologicus as an intentionally unrealistic fiction of sociology but one which is extremely useful and fruitful for - sociological - theory building and intervention. ${ }^{24} \mathrm{He}$ acknowledged that “... the [sociological] assumption that all men behave in accordance with their roles at all times is demonstrably false." ${ }^{25}$ Hence, he rejected an empirical, behavioural, holistic approach to research, even pointing out:

One might infer, therefore, that all sociological theories, in so far as they operate on this assumption [the homo sociologicus], are bad theories; and in fact this point is occasionally made by laymen and even scholars, who do not understand the logic of scientific discovery. In economic theory the protracted argument over whether the homo economicus ... is a realistic image of man's economic behavior has been decided: literal realism is quite unnecessary so long as the

\footnotetext{
${ }^{23}$ For a review of these arguments, see Wagner-Tsukamoto, Human Nature, chapters 2, 3 and 6 in particular.

${ }^{24}$ See Ralf Dahrendorf, Homo Sociologicus (London: Routledge and Kegan Paul, 1973), 7, 50, 58, 78.

${ }^{25}$ Ibid., p. 74; see also Homann and Suchanek, “Methodologische Überlegungen”, 79.
} 
theories based on this model provide powerful explanations and useful predictions. $^{26}$

These arguments can be projected to theological analysis, too. Much theology deals with the analysis of human nature, especially human nature being open towards a "dark side." Mainstream Old Testament theology conceptualizes in this respect Adam and Eve's theft from the tree of knowledge as "sinful behaviour", "tragic behaviour", "immoral behaviour", etc. ${ }^{27}$ If one followed a strict empirical, behavioural interpretation which in this respect could be attributed to theology, some discomforting remarks had to be made. Theology could even be accused of starting the analysis of the human condition with a dark, immoral image of human nature (the thief of the paradise story; the murderer in the Cain and Abel story; the cheat and thief in the Jacob story; and so on). The implied image of human nature may be even darker than that of economics. However, as for economics and other social sciences, I would also argue for theology that such "assumptions" about and "characterizations" of human nature are largely of a tool-like, axiomatic, "heuristic" nature and do not reflect an unrealistic, gloomy or immoral image of human nature. Rather, in the case of theology, they instruct the theological analysis of social problems, as depicted in the Old Testament, and ultimately, they constructively and positively guide practices of Old Testament-based religion. ${ }^{28}$

\footnotetext{
${ }^{26}$ Dahrendorf, Homo Sociologicus, 74; see also ibid., 7, 48, 58, 76-77.

${ }^{27}$ See August Dillmann, Die Genesis Erklärt (Piscataway: Gorgias Press, 2007); Kugel, Bible; Westermann, Genesis 1-11; Samson R. Hirsch, Genesis, transl. Isaac Levy (Gateshead: Judaica Press, 1982); West, Old Testament; Davidson, Genesis 1-11.

${ }^{28}$ For further details, see Wagner-Tsukamoto, God, in particular, section 1.2.
} 
The key thesis I subsequently discuss for the paradise story is that a reconstruction of Genesis 2-3 through the application of the model of economic man yields new, clarifying and fascinating insights into the conceptual logic and structure of this story, especially regarding implied and implicit assumptions of the paradise story on a ban to eat of the tree of life.

\section{Some Preliminary Considerations}

On a first preliminary note, I discuss whether self-interested choice of humans could have had any role to play at all from the outset of human creation in Genesis. An initial insight is that, ultimately, Adam and Eve gave in to "temptation" and stole from the tree of knowledge. The theft reflects that self-interested choice, even in a "worse" manifestation than mere optimizing behaviour in the face of lawfully available choices, is an issue in the paradise story - at least so when the story concludes and the theft happens. However, was self-interested choice also an issue from the outset, once humans began to exist in the Garden Eden? This is clearly the case since, at the outset of human existence, God explicitly issued in Gen. 2:16-17 a - transgressive - ban regarding the tree of knowledge. If Adam and later Eve had not been created in a way that they could have sidestepped the ban, then the ban itself does not make much sense. The possibility of theft and with it the possibility of self-interested choice was thus an issue from the beginning. This insight justifies and legitimizes an economic, rational choice analysis of possibly self-interested behaviour of Adam and Eve as soon as they had been created. 
On a further preliminary consideration, I examine the question whether the tree of life and the tree of knowledge could be or even should be collapsed into one, single tree, namely the tree of knowledge. Some theological interpreters have argued this way. For instance, Krispenz hinted that there may only be enough room for one tree in the middle of the Garden Eden, especially if the idea of the garden were spatially, physically interpreted, so Krispenz. ${ }^{29}$ However, other theological interpreters have suggested that the tree of life is of central importance to the story. ${ }^{30}$ This latter suggestion rests on the insight that God's status of "being divine" reflects the two features of "knowledge of good and evil" and "immortality." The two trees in the middle of the garden symbolized these two features and hence, with it, two motives of the paradise story can be distinguished. Should humans succeed to appropriate both features - by eating of both trees - they would become gods (Gen. 3:22). ${ }^{31}$ Consequently, from what is literally stated in Genesis (that there were two trees in the middle of the Garden) and how this has been interpreted by many theologians (regarding two defining features of divinity) it is fair to conclude that an analysis of two trees makes sense.

Also, it has been suggested that the spare presence of the tree of life in the paradise story, being only mentioned at the outset and the conclusion of the story (in Gen. 2:9 and 3:22-24) indicates insignificance of this tree. ${ }^{32}$ In this connection, I only need the supplementary assumption that there are two trees in Genesis 2-3, which does not appear

\footnotetext{
${ }^{29}$ See Krispenz, "Bäume", p. 304.

${ }^{30}$ See Nicolas Wyatt, "Interpreting the Creation and Fall Story in Genesis 2-3", ZAW 93 (1981), 15-17.

${ }^{31}$ See the literature quoted above on this issue.

${ }^{32}$ See Rad, Genesis; Westermann, Genesis 1-11, 212. Westermann, Genesis 1-11, 186-187, reviews further literature on this issue.
} 
to be critical. ${ }^{33}$ It is not important at the outset of my analysis whether the tree of life is viewed as significant or insignificant. Although, as a result of my analysis, I will argue that the tree of life is considerably more important to the conceptual logic of the paradise story than it has been previously assumed - mainly because the mere presence of this tree implies, on grounds of a rational choice reconstruction, a second ban.

\section{The Tree of Life and Rational, Self-interested Choice}

I unravel the question whether there is, at the outset of the Eden story, an assumed ban regarding the tree of life, despite no such ban being explicitly stated, by starting with the conclusion of the story. In order to turn divine, of becoming gods, Adam and Eve needed to eat fruits of both the tree of life and the tree of knowledge. Gen. 3:22 is here explicit and I quoted supporting literature on this issue above. A critical question is in this respect whether Adam and Eve did know about this issue from the outset. Were they aware that eating of both "divine" trees would change their status of existence from being human to being divine? For one thing, Gen. 2:9 points at Adam and Eve's awareness that the two trees were special and different compared to the other trees. Theological interpreters also hint at the exceptional value of these two trees when suggesting that there were "ordinary trees" in Eden and "two mysterious ones." ${ }^{34}$ Especially centrality in the Garden Eden - being "in the middle of the garden" (Gen. 2:9) - suggests a high value of these trees or at least a higher value as compared to the other trees. Already centrality in itself, being in the middle,

\footnotetext{
${ }^{33}$ See Stratton, Out of Eden, pp. 32-33.

${ }^{34}$ Davidson, Genesis 1-11, p. 33.
} 
should have helped Adam and Eve to distinguish "ordinary trees" from the less ordinary ones. The issue of being ordinary or less ordinary could be further followed up through economic, scarcity-based analysis. Furthermore, there is the explicit ban of Gen. 2:16-17 regarding the tree of knowledge. This ban should have also focused attention of Adam and Eve on both trees since both were in the middle of the Garden and since both trees came as "not ordinary" trees.

We could assume now, as theology conventionally does, that only one tree was banned (the tree of the knowledge of good and evil). What would a rationally acting, selfinterested Adam and Eve do in this situation? Being aware of the special - "mysterious", less ordinary, scarce - nature of both trees in the middle of the Garden, due to them being singled out by centrality and by one tree being explicitly banned, would Adam and Eve hesitate to eat of the tree of life? On grounds of rational choice, it is not even necessary to assume that Adam and Eve knew what specifically singled out the tree of life, namely immortality, in order for them to eat without hesitation of this tree. First, as noted, attention was drawn on the tree of life through centrality and through the ban regarding the tree of knowledge. Second, the expected utility of any sanctions instated by God and thus of "costs" or negative incentives for Adam and Eve for eating of the tree of life was zero (under the assumption that eating of this tree was not banned).

In difference, the death prognosis of Gen. 2:17 involved costs for eating of the tree of knowledge. At the extreme, it implied negative utility - should Adam and Eve actually and instantly die for overstepping the ban. Although, a rational Adam and Eve would discount the death prognosis as not credible, possibly even as irrational, but equally they would 
expect some replacement sanctions for transgression. ${ }^{35}$ Such sanctions subsequently materialized: Humans having to till the soil, eviction from paradise, pains in childbirth, the mortality curse, etc. This implied costs and diminished utility for eating of the tree of knowledge. In this respect, the death prognosis as such may be empty but not God's warning regarding transgression. Hence, an economic reading would stress the speculative nature of the death prognosis: Rather than as a "liar" ${ }^{36}$, God may turn out to be a "rational fool" when he is subsequently outplayed and outwitted by Adam and Eve. ${ }^{37}$

I here do not see as big a puzzle in God's claimed non-fulfilment of his "empty" words as other interpreters have suggested. ${ }^{38}$ Moberley later specifies his terminology regarding the death prognosis as "unreliable" and "untrustworthy"39 which I find much more acceptable. ${ }^{40}$ Issues of rules, their sanctions and their trustworthiness or credibility or the lack of it have been long researched in the institutional economic literature, for instance how a sovereign could establish credible rules which are honoured by subjects. ${ }^{41}$ Such governance issues appear particularly relevant for understanding the paradise story and the Old Testament in general since the Old Testament raises the question of "human life under

\footnotetext{
${ }^{35}$ See Wagner-Tsukamoto, God; Wagner-Tsukamoto, "Paradise Story."

${ }^{36}$ James Barr, "Is God a Liar? (Genesis 2-3) - and Related Matters", Journal of Theological Studies 57 (2006): 1-22; Moberley, "Interpreters"; see also Stratton, Out of Eden, 43.

${ }^{37}$ See Wagner-Tsukamoto, God; Wagner-Tsukamoto, "Paradise Story."

${ }^{38}$ See Moberley, "Interpreters", 23-25, 29.

${ }^{39}$ See ibid., 31-32, 36; see also Moberley, "Serpent", 7, 10.

${ }^{40}$ Barr, "Is God a Liar", 6-8, moves in a similar direction.

${ }^{41}$ See, for instance, Douglas C. North, "Institutions and Credible Commitment", Journal of Institutional and Theoretical Economics 149 (1993): 11-23; Williamson, Economic Institutions; Oliver E. Williamson, "Calculativeness, Trust, and Economic Organization", Journal of Law and Economics 36 1/2 (1993): 453-86; Wagner-Tsukamoto, God.
} 
God" $^{\prime 2}$, as Moberley put this apparent governance issue. Importantly, in the paradise story, the governance relationship with the sovereign "God" is questioned. Through the theft, humans step out of their "creaturely dependence and trust in the creator." ${ }^{43}$ From here it is only a small step to understand the Old Testament as a treatise of social order, which can be reconstructed, for instance, through institutional and constitutional economic governance concepts. $^{44}$

So, however one interprets Gen. 2:17 regarding the ban to eat of the tree of knowledge, a rationally calculating Adam and Eve would expect some costs (which partly or more than fully could be compensated by gaining knowledge once having eaten of this tree). No such costs and decrease in utility due to looming sanctions existed for the tree of life (assuming there was no ban). One could even argue that Adam and Eve should have eaten of the tree of life as a "pre-emptive" strike against the death prognosis of Gen. 2:17. Hence, a rational Adam and Eve would not have hesitated to nearly instantly eat of the tree of life.

However, this hypothesis which rests on the assumption that there was no ban for the tree of life is not compatible with the conceptual structure and storyline of the paradise story. From Gen. 3:22-24 we know that Adam and Eve had not eaten of the tree of life prior to their theft from the tree of knowledge. ${ }^{45}$ And God succeeded in Gen. 3:19 to impose the

\footnotetext{
${ }^{42}$ Moberley, "Interpreters", 39.

${ }^{43}$ Moberley, "Serpent", 24; similarly argues Fromm, Gods.

${ }^{44}$ See Wagner-Tsukamoto, God; Wagner-Tsukamoto, "Slave Contract"; Wagner-Tsukamoto, "Paradise Story."

${ }^{45}$ See also Section 5 of this paper.
} 
mortality curse on Adam and Eve. Otherwise, should have Adam and Eve eaten of the tree of life prior to the theft from the tree of knowledge, they would have already turned into gods at the point of Gen. 3:6 when they stole of the tree of knowledge. ${ }^{46}$ God succeeded after the theft, with some time delay, to impose the mortality curse and protective measures, which safeguarded the tree of life from attack and theft. Consequently, we have to reject the hypothesis that Adam and Eve had eaten of the tree of life prior to their theft from the tree of knowledge - but with this rejection we also have to reject, on grounds of a rational choice analysis, the assumption that the tree of life was not banned from the outset of the story. Only, with the consideration of a ban for the tree of life, expected gains and costs for eating of this tree change - and we need such changes in expected costs in order to coherently explain the actual choice process that is depicted in Genesis.

This rational choice reconstruction implies that mortality and the finiteness of human existence were raised in the paradise story in a more dramatic and more significant manner as conventionally discussed. Besides the death prognosis of Gen. 2:16-17, there was the tree of life which raised the mortality/immortality motive and this important anthropological issue of human nature. In addition, the suggestion of an initial ban for the tree of life elevates the mortality condition of human nature fundamentally and centrally in the paradise story. In this connection, I also question that Adam and Eve had been granted immortality from the outset of creation, possibly even independent of eating of the tree of life. ${ }^{47}$ Hence, the mortality feature is a significant element of the paradise story and the

\footnotetext{
${ }^{46}$ See Section 5 of this paper.

${ }^{47}$ See my further discussion below in Section 5 and the literature quoted then.
} 
paradise story compares much better as previously assumed ${ }^{48}$, to other creation myths which highlight the mortality feature of human nature rather than the feature of autonomy and free choice. Although, it is fair to say, as Davidson, Fromm or Moberley argue ${ }^{49}$, that the paradise story emphasized, through the theft from the tree of knowledge, feature such as human autonomy and independence, even independence of the creator, rather than strive for immortality.

\section{Rational Choice and the Tree of Life: Criticism, Objections and Qualifications}

In the following, I discuss criticism, possible objections and qualifications to the above rational choice reconstruction. In this way, I explicate some of the underlying assumptions of my rational choice reconstruction and I further specify the hypotheses introduced above.

I already discounted the criticism that a self-interested, rational choice interpretation reflected a negative, gloomy or even immoral image of human nature. Whether we interpret the paradise story from an economic point of view or a theological one, we unavoidably meet some "negative" model of human nature with Adam and Eve emerging as thieves of God's banned property. As I suggested, such "negative" models of human nature are instrumentally, heuristically useful for both economic and theological theory building and practical intervention, as different as economic and theological theory and intervention may be.

\footnotetext{
${ }^{48}$ See, for instance, Westermann, Genesis 1-11; Davidson, Genesis 1-11, 34.

${ }^{49}$ See Davidson, Genesis 1-11, 34-35, 48; Fromm, Gods; Moberley, "Serpent", 24.
} 
A concept of rational choice theory is that humans are capable of somehow comparing gains and losses associated with decision alternatives and then choosing, on grounds of self-interest, the option which optimizes personal gain. One could reject this approach by suggesting that Adam and Eve were behaving irrationally or altruistically when making choices. This would imply an exit from economic explanation into a different research programme. This is, of course, legitimate. However, there are not many indications in the paradise story (and neither in most parts of the Old Testament) which justify a view of the irrational or altruistic human being as such, even if some of the outcomes of the paradise story (and other stories, too) may classify as "rationally foolish" from a game theoretical point of view. ${ }^{50}$

Looking at their choices of eating of either or of both "divine" trees, Adam and Eve could gain some positive expected utility by eating of the tree of life (assuming it was not banned); not eating of this tree yielded a zero expected utility. On the other hand, eating of the tree of knowledge came at least with some looming sanctions - at the extreme, death. As I argued, this expectation of sanctions diminishes utility. This was the starting point above which subsequently led me to accept the hypothesis that the tree of life was initially banned. In this connection, we may need the further assumption that eating of the tree of life as compared to eating of the tree of knowledge yielded about same positive utility: If fruits from the tree of knowledge were considerably more valuable than fruits from the tree of life, then a rationally acting God might have safely expected that a ban regarding the tree of life was unnecessary. This suggestion rests on the assumption that expected costs for

\footnotetext{
${ }^{50}$ See Wagner-Tsukamoto, God; Wagner-Tsukamoto, "Slave Contract"; Wagner-Tsukamoto, "Paradise Story."
} 
transgressing the ban regarding the tree of knowledge did not lower the total utility for this act below the expected utility for eating of the tree of life (with no ban existing for the tree of life). In this case, one had to deduce that Adam and Eve's choice attention regarding the "divine" trees was focused, on grounds of rational choice, on the tree of knowledge.

However, various counter-arguments can be raised. For one thing, the tree of life and the tree of knowledge are simultaneously introduced in Gen. 2:9, the tree of life even prior to the tree of knowledge. This may imply similar value, especially so since both trees are conventionally viewed as manifestations of two constituting features of divinity. For another thing, one cannot restrict Adam and Eve's consumption choices to the two "mysterious" trees. If all trees and plants of paradise are viewed as consumption targets, the tree of life is always to stand out at least as the second most attractive choice option and I argued strongly above that it had a positive, expected utility which should have driven a rationally acting, self-interested Adam and Eve to nearly instantly eat of this tree and thus acquire one feature of divinity ("immortality").

My rational choice reconstruction suggested that Adam and Eve had not eaten of the tree of life prior to their theft. Otherwise, so I argued, they would have turned into gods at the point of their theft from the tree of knowledge, they then holding both constituting features of divinity. Counter-arguments exist here in the theological debate, such as the "consumption pattern difference" thesis or the "cut off" thesis. Both imply that no ban was initially in place for the tree of life. I discuss both theses in turn, analysing how convincing they are and what assumptions they rest on in comparison to a rational choice explanation and the suggestion of a ban regarding the tree of life. 
For the tree of knowledge we know that one-off eating was sufficient to acquire the divine prerogative of knowledge of good and evil. If we assume the same one-off consumption pattern for the tree of life, then we have to hypothesize that Adam and Eve had not eaten of the tree of life prior to their theft since they did not turn into gods at the point of the theft from the tree of knowledge. And, hence, on grounds of a rational choice reconstruction, we had to deduce a ban for the tree of life. A considerable body of theological research agrees with the assumption that Adam and Eve had not acquired in any form eternal life or "immortality" prior to their theft (either through eating of the tree of life or even having been initially granted immortality by God). ${ }^{51}$ Gen. 1:27-8 and 2:24-5 strongly hinted at this, too, creating humans in a procreative manner. This implies that immortality had not been initially granted: Only procreation was to ensure "immortality" - in genealogical perspective. I question Engnell or Jobling in this respect. ${ }^{52}$

Still, some interpreters proposed the "consumption pattern difference" thesis in order to argue for immortality being enjoyed by humans in Eden. This thesis suggests that consumption effects regarding fruits from the tree of life and the tree of knowledge are dissimilar; specifically, that continuous eating of fruits of the tree of life was required to maintain immortality for humans. ${ }^{53}$ Under this thesis, one could reinterpret Gen. 2:17:

\footnotetext{
${ }^{51}$ See James Barr, The Garden of Eden and the Hope of Immortality (London: SCM, 1992), 4-8; Barr, "Is God a Liar", 4, 22; Moberley, "Serpent", 15; Moberley, "Interpreters", 25, 34; even Jobling, "Myth and its Limits", 31, agrees, as further discussed below.

${ }^{52}$ See Ivan Engnell, "'Knowledge' and 'Life' in the Creation Story", SVT 3 (1960), 118; Jobling, "Myth and its Limits", 31; see also below.

${ }^{53}$ See Otzen et al., Myths, 50; Engnell, "Knowledge", 116; Rad, Genesis, 76 hints at the mythological origin of this idea.
} 
"Once you steal from the tree of knowledge, you will forfeit your privilege to future eating of the tree of life and thus to immortality."

The hypothesis regarding differing consumption patterns implies various things: First, we have to conceptually and logically accommodate the very idea that there were actually different consumption effects for the two trees. Nothing is explicitly mentioned in Genesis. We need in this respect an additional and rather complex assumption. It is difficult to justify this. Otzen et al. or Engnell do not give any answers in this respect. Second, as I noted above, much theological exegesis does not seem to share the view that Adam and Eve had eaten of the tree of life prior to their theft from the tree of knowledge because, otherwise, so I would specify, they would have turned into gods at the point of the theft (with divinity being defined by eating of both trees). A formidable logistic, sequential problem exists in this regard for the "consumption pattern difference" thesis. Should Adam and Eve have held immortality at the point of their theft from the tree of knowledge - due to a previous, still lasting consumption act regarding the tree of life -, they would have instantly become gods at the point of the theft. Since this did not happen, it has to be deduced that Adam and Eve did not enjoy immortality at the point of the theft. The only way to save the "consumption pattern difference" thesis is to further assume that the immortality granting but only temporary effects of eating of the tree of life "accidentally" expired at the point of the theft. This is a very strong assumption about two logically unconnected events coinciding - unless one wanted to assume a "logical junctim." 54

\footnotetext{
${ }^{54}$ I discuss the "logical junctim" issue below.
} 
Such logistic issues are not considered by Otzen et al. or Engnell. This is especially significant since Otzen et al., quoting Engnell, link Adam and Eve's ceasing access to the tree of life only to Gen. 3:22: "Gen. 3.22 ... must mean: man shall have no longer access to the tree of life so as to retain his personal immortality." ${ }^{55}$ However, a considerable amount of time passed from the point of the theft in Gen. 3:6 until God reacted. For instance, Adam and Eve had time to make cloth (Gen. 3:7), evening came and they were hiding among plants (Gen. 3:8). All this time they did not turn into gods. In this time, Adam and Eve should have enjoyed both constituting features of divinity, had they eaten of the tree of life before, - and, hence, turned into gods.

I also question in this connection a logical junctim between the act of eating fruits of the tree of knowledge and the instant "forfeiting" of a possibly previously held privilege of Adam and Eve to immortality. There is the general problem how one divine prerogative could override the other. But more specifically: First, logically, the paradise story clearly separates two constituting features of divinity from the outset - by introducing two "mysterious" trees in Gen. 2:9. With this, I distinguish two separate motives of the paradise story which are not logically interlinked as such (but the two motives connect through their divinity granting effects - should Adam and Eve succeed to eat of both trees). Second, Gen. 3:24 explicitly prevented Adam and Eve from gaining immortality, with God putting up various measures which secured this tree. The prevention of immortality is thus explicitly linked to not eating of the tree of life but it is not linked to the previous act of eating of the tree of knowledge in Gen. 3:6. Even Otzen et al. and Engnell, as noted, link Adam and Eve's ceasing access to the tree of life to active intervention of God in Gen. 3:24 but not to a

\footnotetext{
${ }^{55}$ Otzen et al., Myths, 50; Engnell, “Knowledge”, 116.
} 
logical junctim between Gen. 2:16-17 and Gen. 3:6 and the immediate loss of immortality as a result of humans eating of the tree of knowledge. Similarly, Stratton affirms that the sense of Gen. 3:22 points towards God's concern that humans may eat for the first time of the tree of life. ${ }^{56}$ We can thus argue that the mortality curse of Gen. 3:19 is only put into effect through God's armaments regarding the tree of life in Gen. 3:24. On these grounds, I am not convinced that the "consumption pattern difference" thesis helps to clarify and simplify the conceptual logic and structure of the paradise story.

The thesis that Adam and Eve held immortality prior to their theft from the tree of knowledge also exists in the literature in a different variant as compared to the "consumption pattern difference" thesis. Jobling suggested that Adam and Eve had been granted immortality from the outset of human existence and that they needed to be cut off from this feature of divinity once they stole from the tree of knowledge. He stated:

"'Knowledge' and 'eternal life' are the twin essentials of divinity. Of the two, the man may possess only one.... [H]aving acquired knowledge, he must be cut off from everlasting life." ${ }^{57}$ The "cut off" thesis is also opposed to a rational choice reconstruction and the proposal of a ban for the tree of life. Like the "consumption pattern difference" thesis, the "cut off" thesis connects to Gen. 2:17. Jobling notes in this connection that all would be logical in Genesis 2-3 “... if [Gen.] 2:17 were to read as 'you shall become mortal'"158, Adam and Eve losing immortality as a logical and instant result of the theft. Jobling, however, admits that the logic of Genesis is not transparent at this point. Still, he argues for

\footnotetext{
${ }^{56}$ See Stratton, Out of Eden, 64; further literature was quoted above.

${ }^{57}$ Jobling, "Myth Semantics", 47; see also ibid., 44.

${ }^{58}$ Ibid., 47.
} 
"permissible and indeed necessary" clarification, specifically "semantic translation" of Gen. 2:17 to "you shall become mortal."

I agree that interpretation and logical clarification are necessary and that the logical structure of the story is unclear at this point. This appears to be generally acknowledged. ${ }^{59}$ However, I favour for various reasons a rational choice reconstruction and the proposal of an assumed, implicit, initial ban regarding the tree of life. First, nothing is explicitly mentioned in Genesis regarding Adam and Eve having been created immortal. The very presence of the metaphor of the tree of life from the outset of the story invokes the motive that immortality was only an aspirational feature of the human condition. Moberley explicitly states this, too, that humans were not created immortal in paradise and that a "cut off" thesis creates considerable problems in analysing and explaining Genesis $2-3 .{ }^{60}$ Second, as I already noted above, already in Eden, Adam and Eve were created procreative (Gen. 2:24-5). This invokes the motive that immortality was to be realized in genealogical perspective rather than being somehow granted in paradise. Jobling even suggests in this connection that human sexuality was no issue inside paradise and hence that "... human continuance depends on immortality; it is essential to the logic of 'inside'." ${ }^{61}$ As noted, Gen. 1:27-8 and 2:24-5 introduced procreation - and with it sexuality, so I would argue, already inside paradise. ${ }^{62}$ Third, as I noted above, a considerable body of researchers disagrees with

\footnotetext{
${ }^{59}$ See, for instance, Dmitri M. Slivniak, "The Garden of Double Messages: Deconstructing Hierarchical Oppositions in the Garden Story", JSOT 27 (2003), 454; Moberley, "Serpent", 15; Rad, Genesis, 96-97.

${ }^{60}$ Moberley, "Serpent", 15.

${ }^{61}$ Jobling, "Myth and its Limits", 31;

${ }^{62}$ This view is supported by Kim I. Parker, "Adam: The Postmodernist Bourgeois Liberal?", JSOT 29 (2005), 449; Stratton, Out of Eden, 206-207; Graham Ward, "A Postmodern Version of Paradise",
} 
the view that Adam and Eve had held immortality prior to their theft from the tree of knowledge. Fourth, we encounter again the logistic problem, this time even in an aggravated version since we cannot assume that immortality accidentally expired at the point of the theft. Regarding the way the paradise story unfolds after the theft, a considerable amount of time elapsed before God noticed the theft and then intervened putting up actual measures, in Gen. 3:24, which only then credibly prevented Adam and Eve to eat of the tree of life. This is a strong argument against a logical junctim between Gen. 2:16-17 and Gen. 3:6, immortality ceasing instantly as an immediate result of the theft itself. Indeed, if immortality had already ceased at the point of Gen. 3:6, there would have been no need for protective measures and deterrents to be put up around the tree of life in Gen. 3:24 and neither is there a need for the mortality curse of Gen. 3:19. This argument regarding immediate effects is strengthened since we know that the effects from eating of the tree of knowledge - regarding acquiring knowledge of good and evil - actually did take immediate effect, as Gen. 3:7 outlines.

Should Adam and Eve have held immortality at the point of the theft from the tree of knowledge, we need not just a "cut off" hypothesis with God later reacting; rather, we need an "immediate action" hypothesis with God instantly intervening and confiscating the privilege of immortality of humans. Indeed, even with instant action after the theft, the question remains would we not see various gods battling against each other since the theft already had taken place? And from a theory building point of view, would the paradise story not have ended with humans turning gods? If one wanted to save the "cut off" thesis (1988), 120. 
logistically, the last moment at which cutting off from immortality could have safely happened was immediately prior to the theft. ${ }^{63}$

In later publications, Jobling slightly recasted his argument but this, in my view, did not solve the earlier problems regarding the "cut off" thesis. He explicated:

It [eternal life] was present inside the garden (2.9), and not forbidden to man (2.16-

17). It is not said that he actually ate of it - this would create narrative difficulty since it would mean that he had gained immortality indelibly - but the situation can be translated mythically as "immortality belonged to the man inside the garden." Only after his eating of the tree of knowledge does it become necessary to keep him from eating of the tree of life. ${ }^{64}$

The statement reflects Jobling understanding of immortality "belonging" to Adam and Eve inside paradise. I agree with Jobling that there were two trees at the outset, symbolizing two constituting features of divinity and that only one was explicitly banned. Jobling also disagrees with the "consumption pattern difference" thesis when suggesting that one-off eating would have been sufficient to ensure immortality for humans indefinitely ("indelibly"). However, Jobling explicitly states that the tree of life was not banned and that at the same time humans did not eat of this tree. This reflects Jobling reading of "belonging" when he speaks of "immortality belonging to man inside the garden" but Adam and Eve actually having not eaten of the tree of life. He points towards "mythic translation" of

\footnotetext{
${ }^{63}$ A further implicit assumption to my argument is here that "human" divinity and "godly" divinity are not significantly different, for instance, one being superior to the other and thus possibly capable of stripping the other of certain divine prerogatives.

${ }^{64}$ Jobling, "Myth and its Limits", 31, emphasis as in original.
} 
"belonging", specifying, similar to Jobling "semantic translation"65, that Gen. 2:17 means "in the day that you eat of it [tree of knowledge] you will become mortal." ${ }^{66}$ In Jobling interpretation, this implies that the act of eating of the tree of knowledge logically "confiscates" the privilege towards immortality inside paradise which, according to Jobling, had not been consumed by Adam and Eve but only "belonged" to them.

A rational choice reconstruction of a ban regarding the tree of life does away with the complex and in my view logically inconsistent suggestion that immortality had somehow belonged to Adam and Eve inside paradise but that they had actually not consumed fruits from the tree of life. In addition, a rational choice analysis addresses the other issue raised against Jobling position: I question the concepts of "mythic" and "semantic" translation and the conceptual implications this has regarding a logical junctim between Gen. 2:16-17 and Gen. 3:6. I discounted such a logical junctim already above. Such a junctim assumes much more than the reconstruction of a ban for the tree of life on rational choice grounds. The concluding point I want to make is that from a rational choice point of view, it is inconceivable that Adam and Eve had not eaten of the tree of life prior to their theft from the tree of knowledge - unless the tree of life was banned. In my analysis, already from the outset, Adam and Eve need to be kept - through a ban - from eating of the tree of life since only a ban, similar to the one of Gen. 2:16-17, changes expectations of gains and losses in relation to eating of the tree of life. Conceptually, we need such changes in expected costs regarding eating of the tree of life in order to bring events in Genesis 2-3 to the conclusion we actually find described in the Old Testament.

\footnotetext{
65 Jobling, "Myth Semantics."

${ }^{66}$ Jobling, "Myth and its Limits", 31.
} 
So, however one turns this issue of a possibly differing consumption pattern for the tree of life as compared to the tree of knowledge, or immortality being somehow enjoyed by ("belonging to") Adam and Eve prior to the theft, such approaches need to invoke various and rather complex, additional assumptions in order to explain Genesis 2-3. This leads to a less parsimonious, logically less transparent and conceptually less convincing explanation than the one I proposed through a rational choice reconstruction and the suggestion of a ban for the tree of life.

\section{Conclusion}

The paper underlined the usefulness and insightfulness of an economic interpretation of the Old Testament. Rational choice concepts, such as self-interested behaviour of humans, are widespread in the paradise story (and in subsequent stories). In addition, the Old Testament targets self-interest on the side of God. For instance, in the paradise story, we find the explicit ban regarding the tree of knowledge. It implies that we are dealing, as theology noted, with a self-interested God, who fulfils his own wants, and who guards his own privileges. ${ }^{67}$ This apparent prevalence of "negative" models of divine and human actors in the Old Testament, which compare to economic man, should encourage future research into the role of concepts like economic man in the biblical text. It should also encourage theology to examine reservations against the model of economic man, especially so since in generic heuristic, methodological perspective, theology and economics may not be too dissimilar when it comes to modelling and analyzing a "dark" side of the human condition.

\footnotetext{
${ }^{67}$ See Jobling, "Myth Semantics", 42; Fromm, Gods, 159; see also Wagner-Tsukamoto, "Slave Contract"; Wagner-Tsukamoto, "Paradise Story."
} 
The paper demonstrated that there is clearly a case regarding an assumed, initial ban for the tree of life. My analysis suggested that an economic, rational choice reconstruction and the proposal of an initial ban for the tree of life clarifies the logical structure of Genesis 2-3 and resolves some of the conceptual ambiguities that surround the Garden story. There are various critical passages in Genesis which led me to suggest, on grounds of a rational choice reconstruction, that Adam and Eve must have been banned from the outset of human existence in paradise not to eat of the tree of life. First, there is Gen. 2:9 when the two "divine" trees are introduced at the same time and their special status is highlighted in comparison to other plants. I interpreted this as the introduction of two, separate motives of storytelling in Genesis. The trees are singled out and a rationally calculating, selfinterested Adam and Eve should not have hesitated, prior to their theft from the tree of knowledge, to eat of the tree of life - unless there was a ban in place which changed their rational calculations of expected gains and losses. The assumption that there was no ban in place convolutes the logic and consistency of the story, especially so once the theft from the tree of knowledge happens in Gen. 3:6, and God only later takes explicit measures in Gen. 3:22, 24 to prevent Adam and Eve from acquiring the "other" feature of divinity. ${ }^{68}$

Second, Gen. 2:17 explicitly banned Adam and Eve not to eat of the tree of knowledge with the death prognosis being attached to the ban. However one turns it, there seems to be general agreement that Gen. 2:17 cannot be interpreted literally, largely because actual death did not materialize as a result of the theft. Clarifying assumptions are needed regarding the discrepancy between the death prognosis of Gen. 2:17 and the actual sanctions that followed. The big puzzle (or at least, another big puzzle), so I argued, is

\footnotetext{
${ }^{68}$ See below.
} 
whether the two constituting features of divinity, as they are symbolically and separately raised in the paradise story through the tree of life and the tree of knowledge, are conceptually and logically interlinked through the ban of Gen. 2:17 and its death prognosis. I discounted such a logical junctim on grounds of what actually happened in Gen. 3:6 and in Gen. 3:22, 24 (See also below).

Third, in Gen. 3:6-8, Adam and Eve broke the ban regarding the tree of knowledge and time elapsed before God discovered that the ban had been broken and then intervened. Importantly, Adam and Eve did not turn into gods at the point of Gen. 3:6. This sequence of events and the lapse of time undermine the suggestion of a logical junctim between the death prognosis of Gen. 2:17 and Gen. 3:6, and that Adam and Eve had prior to Gen. 3:6 somehow enjoyed immortality in Eden. Hence, I merely interpret the "you will die" of Gen. 2:17 as the warning of sanctions to be instated for transgression. We find such sanctions in Genesis once the ban was broken (eviction from paradise; humans having to till the soil; pains in childbirth; the mortality curse; etc.).

Fourth, in Gen. 3:22-24, God took explicit, physical measures, not relying on mere bans and "warnings" any longer, to secure the tree of life. The mortality curse of Gen. 3:19b was in this respect enforced through God's armaments of the tree of life in Gen. 3:24. In this regard, I find no conceptual difficulty and nothing strange in the tree of life explicitly reappearing in Gen. 3:22-24, as Rad or similarly West claimed. ${ }^{69}$ I interpret this reappearance of the tree of life as a further indication that this tree reflects a logically separate motive of the paradise story, that this tree must have been subject of an initial

\footnotetext{
${ }^{69}$ See Rad, Genesis, 94; West, Old Testament, 87.
} 
ban, and that the defense mechanisms, armaments and enforcements of Gen. 3:24 for the tree of life now credibly substantiated an initial ban as well as the newly imposed mortality curse of Gen. 3:19b. Furthermore, God's worry, as expressed in Gen. 3:22, that humans could become fully like gods by eating from the tree of life, is appeased only at the point of Gen. 3:24. Should humans now dare to eat of this tree, instant death would follow without God having to intervene, death being enforced through the flaming sword and the cherubim - the "divine security guard"70, who acts on God's authority. The present paper contributed in these respects also to a considerable clarification of the last three verses of Genesis 3, for which, according to Westermann, the state of biblical scholarship has been very confused. ${ }^{71}$

Interestingly, even at this late point of Gen. 3:22-24, when we can explicitly observe the introduction of armament measures, sanctions for transgression, and enforcements regarding the protection of the tree of life, Genesis does not explicitly state a rule or "ban" not to eat of the tree of life. Such a rule should read as: "You shall not eat of the tree of life or you will be killed." In a figurative sense, Gen. 3:19b may hint at such a rule but only if one interpreted the mortality curse widely and prescriptively rather than narrowly and descriptively. Rad seemingly followed such a wide, prescriptive interpretation when suggesting: "Could man at all, after his sentencing [in Gen. 3:19b], break through the ban of death ?"72 $^{72}$ Other interpreters have suggested that the mortality curse of Gen. 3:19b only means that humans were "worn out" by the previous curses imposed on them, through

\footnotetext{
${ }^{70}$ Davidson, Genesis 1-11, 48.

${ }^{71}$ See Westermann, Genesis 1-11, 271.

${ }^{72}$ Rad, Genesis, 94.
} 
Gen. 3:17-19a. ${ }^{73}$ Still, a rule like "You shall not eat of the tree of life or you will be killed" is at least implied by the death sanctions of Gen. 3:24. In general, it is inconceivable to think of sanctions without rules but there may be rules without any or without credible sanctions and enforcements - and this seems to be much the story of Gen. 2:16-17. So, even at this late point, Genesis is comparatively implicit regarding a rule or "ban" not to eat of the tree of life. As I argued through my rational choice reconstruction, such "implicity" regarding a rule not to eat of the tree of life needs to be projected back right to the beginning of the paradise story when both "mysterious" trees were introduced and only one of them was explicitly banned.

With regard to these passages in Genesis, I clarified the conceptual ambiguity and logical inconsistency that exists in Genesis 2-3 regarding the two "divine" trees, especially regarding Gen. 2:16-17 when explicitly only one ban is put up, and also with regard to Gen. 3:22 when the tree of life explicitly becomes the concern of God and is subsequently protected in Gen. 3:24. I claim in this connection that a fundamental crux interpretum in Genesis 2-3 is not necessarily focused on Gen. 2:16-17 with the question of whether it implied immediate death. On grounds of my discussion, I would recast the crux interpretum of Genesis 2-3 with respect to the question whether a ban regarding the tree of life is conceptually required - and addressing this question helps us to considerably clarify Genesis 2-3.

I can sharpen my key argument through the thesis that the paradise of Genesis was essentially defined through two bans: The Eden story needs a second ban not only in order

\footnotetext{
${ }^{73}$ See Stratton, Out of Eden, 61-62, 138; similarly Westermann, Genesis 1-11, 266-267.
} 
to preserve its logic and consistency but also to raise, from the outset, fundamental issues of a human anthropology of the finiteness of human existence. This also implies that the "second" tree, the tree of life, is of central need and significance to the paradise story (and subsequent stories in the Old Testament, too). Subsequent stories of Genesis and the Old Testament address this issue of immortality not only when the tree of life is again explicitly mentioned in the Old Testament (Prv. 3:18; 11:30; 13:12; 15:4) but also when mortality in any version is discussed. In this connection, the tree of life and mortality / immortality even enter contractual negotiations and the covenants between God and humans, especially so when patriarchal leaders are rewarded with longevity and when their genealogies unfold. In this respect, the genealogies set out in Genesis metaphorically reflect the tree of life (e.g. Gen. 5:1-32). Similarly, as does the longevity of biblical figures - Adam, for instance, is reported to have reached the age of 930 years (Gen. 5:5) - figuratively invokes the tree of life. In this way, the tree of life is widely present throughout the Old Testament, at least much more so than a strict literalist interpretation of the biblical text could unearth. Immortality is then not as taboo to humans as Krispenz or similarly Rad claim. ${ }^{74}$ Hence, I fundamentally disagree with theological interpreters like Krispenz who suggested that the path to the tree of life could only be reopened through the New Testament and a Christian theology with its belief into resurrection. ${ }^{75}$ If carefully read, there are manifold, metaphorical and figurative references in the Old Testament to the tree of life and immortality.

\footnotetext{
${ }^{74}$ See Krispenz, "Bäume", 314-315; Rad, Genesis, 76.

${ }^{75}$ See Krispenz, "Bäume”, 317.
} 
As acknowledged, Genesis explicitly states nothing regarding a ban not to eat of the tree of life. On grounds of a rational choice reconstruction, we can explain this absence as a logical, conceptual omission of those who were involved in writing and redacting the paradise story before it reached the version which is known to us. We may speculate that a second ban was "overlooked" by the early writers and redactors of the Old Testament or that it was there but got lost in early or later redaction processes. The historic roots of the Eden story in creation myths that emphasize the immortality / mortality feature and a ban regarding immortality is well known. Also, early or later redaction could even have intentionally written out such a ban from the paradise story since the goal was to shift conceptual analysis in the Old Testament on the knowledge feature, especially moral knowledge for setting up social contracts among humans and between humans and God. But with the writing out of a second ban, the redactors allowed conceptual inconsistency into the paradise story. Future research into the history of the redaction process of the paradise story can address this important question on how the second ban got "lost." 